\title{
Investigation of Flame Retardant rPET Foam
}

\author{
Veronika Anna Szabó1, Gábor Dogossy ${ }^{1 *}$ \\ ${ }^{1}$ Department of Materials Science and Technology, Audi Hungaria Faculty of Vehicle Engineering, Széchenyi István University, \\ H-9026 Győr, Egyetem tér 1, Hungary \\ * Corresponding author, e-mail: dogossy@sze.hu
}

Received: 17 June 2019, Accepted: 30 June 2019, Published online: 11 October 2019

\begin{abstract}
The use of plastics in the food and the packaging industries continuously is increasing. In these areas of use the product's life cycle is short, therefore it quickly turns into waste. The polyethylene terephthalate (PET) - the material that is used as beverage containers are the material with the greatest environmental load. The physical recycling of PET bottles in large quantities was the research goal. During the work with the help of chemical foaming a closed cell structural foam from PET bottle was produced. The research was carried out with upcycling using chain extender and impact modifier additives. For industrial use a bromine-based flame retardant was used and excellent flame retardancy was achieved. Based on the results obtained, the material previously managed as waste, with the appropriate treatment can be involved into the manufacturing of new products.
\end{abstract}

Keywords

recycled PET, flame retardant, chemical foaming, CT

\section{Introduction}

The world's total plastic consumption can be divided into five main branches: construction, automotive, electrical and electronics, agriculture and packaging. The production of polyethylene terephthalate (PET) bottles has taken grandiose sizes. In 2016, more than 480 billion plastic bottles were sold worldwide, which has increased exponentially since. Euromonitor International's global packaging trends estimate that by 2021 the number of plastic bottles will increase to 583.3 billion [1].

The primary solution for eliminating the environmental load caused by PET bottles is recycling. An important research task is the production of composites that improve the mechanical properties of the raw material and provide the opportunity for recycled polyethylene terephthalate (rPET) to be used in large quantities. In PET recycling, there are three different occurrences if chain-scissions, they are as a result of mechanical, thermal and hydrolysis. In the recycling of PET, this phenomenon is a major problem in both processing and re-use [2].

Coccorullo et al. [3] investigated the effect of PMDA chain-extender additive on foamed structure during the extrusion of recycled PET. In terms of viscosity, the chain extender has shown an increasing growth. In contrast, in high shear rates there could be no such differences are in lower shear rate.
Karayan [4] tested the applicability of the Cesa Extend chain-extender masterbatch to improve the extrudability of recycled PET. The pure and chain extender added recycled PET film was compared during extrusion. The deflection had been defined as the vertical distance between the lowest point of the extrudate and the die. As the amount of chain extender added increased, the degree of drooping decreased significantly. It was found that using $2 \%$ of chain extender, the extrudate moved horizontally from die to calender.

Turfa et al. [5] investigated the effect of chain extenders on the flowability of PET. It has been found that the $1 \%$ additive significantly increases the length of the polymer chains, while $2 \%$ increases the frequency of branching within the molecular chain, thanks to the multi-functional molecular structure of the chain-extender additive. However, further increase in the ratio of chain extender is not recommended as this may cause undesired crosslinking resulting in gelling, leading to deterioration of processing properties. In general, it has been found that by using a suitable ratio of chain-extender additive, the viscosity of the material is increased during processing and the mechanical properties of the item are improved.

It is possible to increase the impact resistance by adding rubber-elastic additives. The functionalized end group of the reactive additives improves the bonding of the PET 
to the matrix and provides a better distribution by changing the interface energy between the matrix and the additive. Ronkay and Kasza [6] have therefore tested the use of Du-Pont Elvaloy PTW-type impact modifier additive for recycled PET. Based on their research, it was found that the impact strength of the material was adequately increased with the addition of $10 \%$, coupled with an acceptable tensile strength and tensile modulus.

An important condition for the widespread use of plastics is to increase the flame resistance of the material [7]. We use flame retardants to reduce the speed and spread of fire. Emerging heat, toxic gases, and the resulting smoke endanger human life. To meet the increasingly stringent flammability requirements and regulations we have added a variety of flame-retardants to the raw material. Flame retardant additives must provide adequate stability under processing conditions. It must be compatible with the polymer used so that it does not impair its properties. The main goal is to keep the flame retardant in the lowest possible concentration.

Szolnoki et al. [8] wanted to improve the fire resistance of the epoxy resin to combustion using a phosphorus additive. During their development, a reactive flame retardant containing 9,10-dihydro-9-oxa-10-phosphafenanthrene-10oxide (DOPO) was created. The results of the developed flame retardant were compared with a recently synthesized phosphorus-containing reactive amine (TEDAP) and a commercially available Nordmann Rassmann flame retardant containing ammonium polyphosphate. Their results show that DOPO is not able to significantly reduce the combustion of epoxy resin due to its molecular incompatibility. In contrast, the results of the UL 94 test indicate that the flame propagation rate is reduced when used, if only to a small extent. Further, the material reached its peak temperature later. It has been found that TEDAP is a more effective flame retardant than the currently available ammonium polyphosphate-containing flame retardant.

Bromine-containing flame retardants are currently market leaders, and are likely to remain so for years, due to their favorable price and efficiency [9]. In bromine-containing flame retardants, due to heat bromide free radicals are formed which react with the hydrocarbon molecules and produce hydrogen bromide. This reduces the amount of flammable gases in the combustion chamber, and the carbonization of the material begins. At the end of the reaction, additional free bromide radicals are still available. Complete flame retardation consists of repetitive cycles. The process is repeated until the burn is over.
In their research, Ronkay et al. [10] experimented with increasing the flame resistance of rPET. Resistance to rPET nanocomposites has been improved using montmorillonite (MMT) produced by a combination of aluminum-alkyl-phosphine (AlPi) flame retardant and natural blend. Natural montmorillonite (oMMT) modified with hydrogenated tallow-alkyl-dimethyl-salt was also tested in the experiments. Their results have shown that rPET achieves the requirements of UL-94 V0 flammability class with $4 \%$ flame retardant and $1 \%$ MMT or oMMT. Conversely, based on both the flammability test and the LOI index, the use of modified oMMT is recommended. With the use of the developed flame retardant, the rPET's flexural strength and modulus have been greatly improved and the impact resistance of the material has deteriorated.

Xue et al. [11] experimented with the production of PET-based flame retardants in their research. A flame-retardant additive was developed in which the two capsule walls of carbon microspheres were provided by an inorganic magnesium hydroxide $(\mathrm{MH})$ inner shell layer and a PET outer shell layer. The microencapsulated flame retardant (PMCMS) was subjected to in-situ polymerization which was homogenized by extrusion with PET granulates. Compared to the original PET, the best-performing $2 \%$ PMCMS showed a $22.41 \%$ improvement in ignition rate. It produced $31.38 \%$ better results when measuring the amount of heat emitted. In addition, the fire performance indicator was improved by $13.09 \%$, while total smoke production was reduced by $21.52 \%$.

The foam structure is designed to increase the flame resistance in the material. In recent years, foamed structures of polymers have become increasingly prominent. The primary reason for this is that polymer foams are widely used. By changing the structure of the material, we can achieve ideal properties, such as low weight or flame resistance.

In their research, Ghaderian et al. [12] used PET flakes to produce rigid polyurethane foams (RPUFs). Propylene glycol was added to the raw material in different proportions. This was reacted with polyethylene-diphenyl-diisocyanate by two steps blowing. As a result of the analysis of the prepared foams, it was found that the foamed structure of rPET has similar thermal and mechanical properties as commercially available RPUF foams.

Carosio et al. [13] experimented with the fire resistance of closed cell foamed PET in their research. They used pre-manufactured physically expanded PET as the raw material for their research. The Layer by Layer method was used to form the flame-retardant layer. 
The best-performing sample was the four-layer ammonium polyphosphate-based flame-retardant coating, which reduced the maximum burning heat by $25 \%$.

In our previous research [14], we attempted to produce the foam structure of rPET by chemical foaming on a conventional injection molding machine. Several chemical blowing agents were tested while selecting the ideal additive to produce a closed cell structure.

For the development of foam, $2 \%$ CESA Extend chain-extender and $10 \%$ impact modifier was added to the material. The chain extender alone did not produce the desired results to improve mechanical properties. On the other hand, the addition of an impact modifier, we have seen significant improvements in the mechanical properties of the material [15].

In this article, we study the effect of flame retardant on the foam structure and flammability of foamed rPET.

\section{Materials and methods}

During the experiments, commercially available blue crystallized PET re-granulate (rPET) (Fe-Group Invest, Budapest, Hungary) with an intrinsic viscosity (IV) value of $0.8 \mathrm{dL} / \mathrm{g}$ was used as matrix material. CESA Extend NCA0025531-ZA (Clariant, Muttenz, Switzerland), which contains Joncryl ADR 4368 (Johnson Polymers, Studley, UK) type epoxy-based styrene-acrylic multifunctional oligomer reagent was applied as chain extender additive. Elvaloy PTW (Du-Pont, Midland, USA) type ethylene terpolymer (63\% ethylene / $31 \%$ buthyl achrylate / $6 \%$ glycidylmethacrylate) was utilized as impact modifier additive. ICH Fl ret 01904 (ICC-Chemol, Budapest, Hungary) with $85 \%$ dispersion of brominated organic compound in ethylene co-polymer was used as flame retardant additive. Tracell IM 7200 (Tramaco, Pinneberg, Germany) endothermic compound with $120 \mathrm{ml} / \mathrm{g}$ gas expansion and $70 \%$ blowing agent content was utilized as chemical blowing agent.

The rPET was dried for $24 \mathrm{~h}$ at $100{ }^{\circ} \mathrm{C}$, and then mixed together with the additives. LT 20-440 (Labtech Engineering, Samut Prakan, Thailand) twin-screw extruder was applied for the mixing with a melt temperature of $265^{\circ} \mathrm{C}$. The produced regranulate was dried for another $12 \mathrm{~h}$ at $100{ }^{\circ} \mathrm{C}$, then standard dumbbell specimens (with $4 \times 10$ cross-section) were prepared by an Allrounder Advance 420C Golden Edition (Arburg, Lossburg, Germany) injection molding machine with breathe molding technique, with the following parameters: melt temperature: $265^{\circ} \mathrm{C}$, injection speed: $45 \mathrm{~cm}^{3} / \mathrm{min}$, mold temperature: $35^{\circ} \mathrm{C}$. Table 1 shows the composition of the test samples.
Table 1 The compositions of the test samples

\begin{tabular}{lcccc}
\hline & ref & A-0 & A-5 & A-20 \\
& \multicolumn{4}{c}{ parts per hundred (phr) } \\
\hline rPET & 100 & 100 & 100 & 100 \\
Chain Extender & 0 & 2 & 2 & 2 \\
Impact Modifier & 0 & 10 & 10 & 10 \\
Chemical Blowing Agent & 4 & 4 & 4 & 4 \\
Flame Retardant & 0 & 0 & 5 & 20 \\
\hline
\end{tabular}

The viscosity was determined using Ceast MF-30 modular MVR tester with $2.16 \mathrm{~kg}$ load at $280^{\circ} \mathrm{C}$.

The density was determined based on the Archimedes principle using Ohaus Explorer analythical balance.

The inner structure of parts was investigated with an industrial X-ray CT equipment type YXLON Modular with a resolution $0.027 \mathrm{~mm}$, tube voltage $200 \mathrm{kV}$, tube current $0.1 \mathrm{~mA}$. Detection was carried out using a flat panel, $700 \mathrm{~ms}$ integration time, without filter. A total of 1440 projection images were taken for reconstruction. Software VGStudio MAX 2.2 was used to determine the porosity and the diameter of cells.

Tensile tests were executed using INSTRON 5582 type (Instron, Norwood, USA) universal testing instrument with $100 \mathrm{~mm}$ grip length according to EN ISO 527 standard. The test speed was $1 \mathrm{~mm} / \mathrm{min}$ when determining the modulus and $5 \mathrm{~mm} / \mathrm{min}$ when determining the tensile strength.

Three-point-bending tests were carried out using INSTRON 5582 type (Instron, Norwood, USA) universal testing instrument according to EN ISO 178 standard. The test speed was $10 \mathrm{~mm} / \mathrm{min}$, support span was $64 \mathrm{~mm}$.

Charpy impact tests were conducted by a CEAST 65-45,000 type machine (Ceast, Pianezza, Italy), using unnotched specimens, according to EN ISO 179 standard. The measurements were performed with a pendulum of $15 \mathrm{~J}$ and with $62 \mathrm{~mm}$ support span.

Five specimens were tested for each sample to obtain a reliable average of studied properties, as well as their corresponding standard deviations. The tests were implemented at room temperature with relative humidity of $50 \%$.

Standard UL-94 tests were performed in a chemical fume hood with methane gas. Specimen thickness was $4 \mathrm{~mm}$. UL-94 classification is used to determine dripping and flame spreading rates. First, horizontal burning tests were carried out. As long as the burning rate did not exceed $40 \mathrm{~mm} / \mathrm{min}$ over a $75 \mathrm{~mm}$ span, the specimen got HB classification. If the burning stopped before it reached the $25 \mathrm{~mm}$ mark on the specimen, then the vertical burning test was conducted as well. 


\section{Results}

The following section describes the properties of samples of different compositions. In our experiments we analyzed the effect of flame retardant on foam structure, mechanical properties and flammability.

\subsection{Morphology}

The closed cell foam structure formed by chemical foaming provides the best properties when small sized, large numberes and homogeneously dispersed cell structures are created. For this, it is essential for the used material to have a sufficiently high viscosity. When using a low viscosity polymer, the growth of the cells due to chemical foaming can be rapid and easily merging, resulting in large cells and an unordered cell structure. This, in turn, greatly reduces the resistance of the material to mechanical stress. The chain-scission characteristic of PET recycling results in low viscosity, so we used a chain-extender additive in our experiments to increase the viscosity. The use of flame-retardant additives also had a positive effect on the viscosity value (Fig. 1). High viscosity inhibits gas cell collapse, resulting in finer distribution of foam in higher viscosity material. One of the positive effects of foaming is weight loss. The density of the specimens is reduced due to the cell structure that has been formed, but the degree of decrease is greatly influenced by the viscosity of the material (Fig. 1).

The use of the chain-extender had a positive effect on the material's viscosity and improved the foam structure. Conversely, due to the use of the impact modifier, the density of the products produced increased, due to the additive ethylene-terpolymer carrier. The addition of flame-retardant increased the viscosity of the blends, with a $5 \%$ flame retardant application, the viscosity increased nearly sixfold. It is also seen that the use of a flame-retardant in a low percentage by weight significantly affects the viscosity of the material.

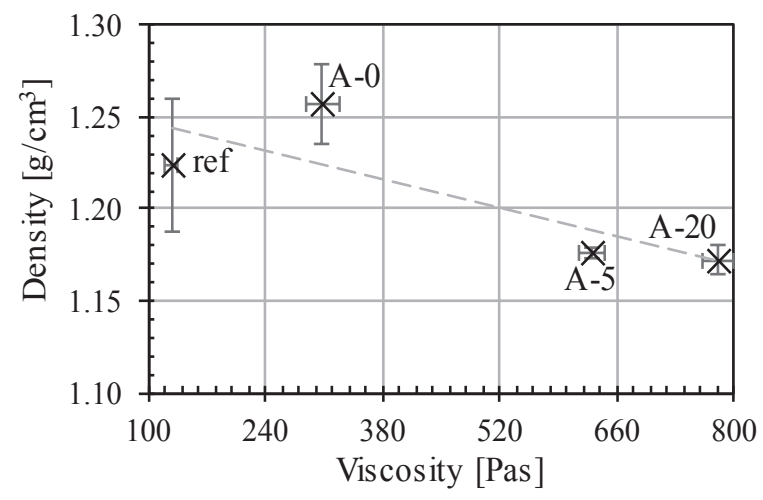

Fig. 1 The effect of viscosity on density
The highest viscosity had been reached with the $20 \%$ flame retardant material. Density testing showed minimal variation between the 5 and $20 \%$ materials.

Based on the relationship between porosity and density of the samples, it can be stated that the density of the pieces increased with increasing porosity (Fig. 2). The lowest density values were the samples with low porosity and flame-retardant additive. This is probably due to the low density of the ethylene copolymer carrier of the flame-retardant additive.

In our experiments, we developed an integral foam structure. It can be observed that the cell diameter is continuously changing along the cross-section. The outer layers that met the wall of the tool solidify first, thereby forming a porous, solid shell on the surface of the finished product, which becomes more porous towards the core. By increasing the flame-retardant ratio, the cell diameters changed in a reverse rate to viscosity (Fig. 3).

There were no exceptionally high values between cell diameter data in samples containing flame-retardant. The diameter of the largest cell did not exceed $150 \mu \mathrm{m}$, and the number of cells of larger diameter was much lower than that of the other two samples tested. Thanks to this, no collapsed cells were created, and no larger cavities

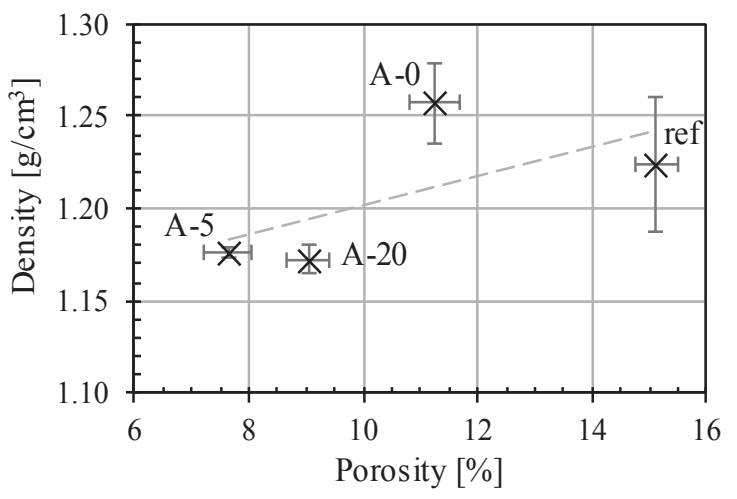

Fig. 2 The effect of porosity on density

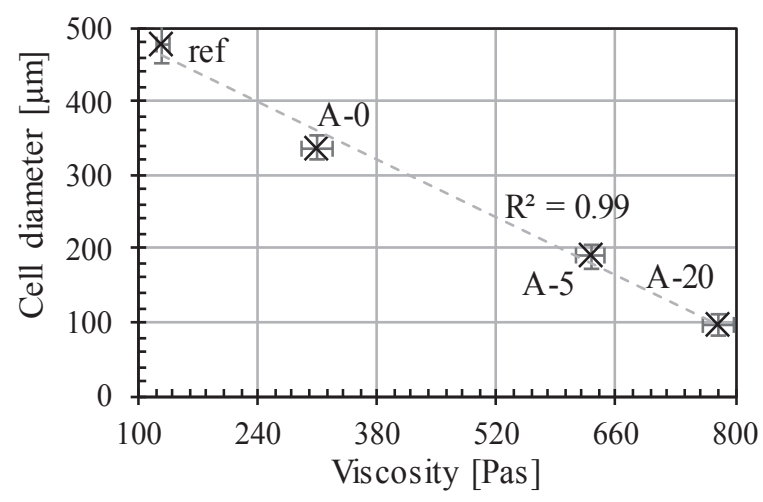

Fig. 3 The effect of viscosity on cell diameter 
were expected in the middle of the core. This is an important advantage, so the larger cavities are less likely to be created during the manufacturing process, which would serve as stress concentration location, thus hazarding the mechanical load capacity of the material.

Fig. 4 shows CT model of a sample containing $5 \%$ flame retardant. The integral foam structure has been developed with the use of flame-retardant additives. Moving toward the core, the diameter of the cells increases. Cells near the wall have a smaller diameter.

The use of only $5 \%$ flame-retardant has already resulted in a more orderly cell structure. There were many more small cells in the sample. This may be related to the result of the dynamic viscosity measured during the MVR test. On the CT image, we can see that a thinner shell wall was created by increasing the proportion of flame-retardant.

\subsection{Mechanical properties}

As a result of foaming, a brittle material had been created from the originally ductile raw material.

Fig. 5 shows the results of the tensile test. Measurements show that both the tensile strength and the tensile modulus have been improved with the use of the chain extender and the impact modifier. The use of a chain extender has helped to create a more stable foam structure, resulting in reduced deviation range in the samples. With respect to the modulus of elasticity, we can see that the use of different additives has a smaller variation than in the case of tensile strength. In addition to the use of flame-retardant, the modulus of elasticity has a declining trend, which is increasingly a drop with increasing the flame-retardant ratio. For samples with only chain-extender and impact modifier additives, there was the smallest standard deviation due to the foam structure resulted from the effect of chain-extender. In the case of the reference foam, due to the large diameter of the cell, the material reacted poorly to the pulling force. In the case of the two samples containing the flame retardant, the material breaks at different stresses due to the broader cell distribution. The lowest tensile strength of the samples developed with the additive was demonstrated by specimens containing $20 \%$ of flame-retardant. The primary reason for this is that the samples have a much thinner shell thickness than the other groups tested. The portions between well-spaced cells formed alongside the stable foam structure do not respond well to the tensile load. In general, the use of flame-retardant has a negative effect on the tensile stress of the rPET foam.
The foam structure has a negative effect on the three-bending test results (Fig. 6). With respect to the flexural modulus, the improvement achieved by the combined application of the chain-extender and the impact modifier is greatly reduced using the flame-retardant. The tested specimens were minimally bent during the test due to the foam structure, and subsequently suffered fracture. During the flexural test, the results were greatly influenced by the cell density of the cross-section of the surface pressed by the bending tool. This is supported by the standard deviation of the results. For non flame-retardant

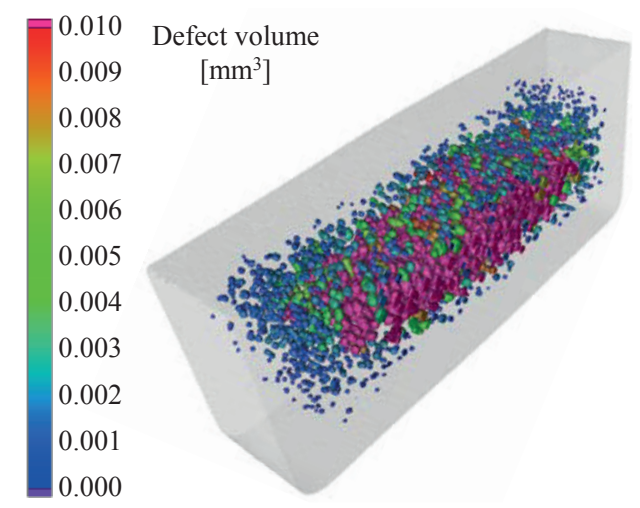

Fig. 4 The CT image of A-5 sample in a $2 \mathrm{~mm}$ section

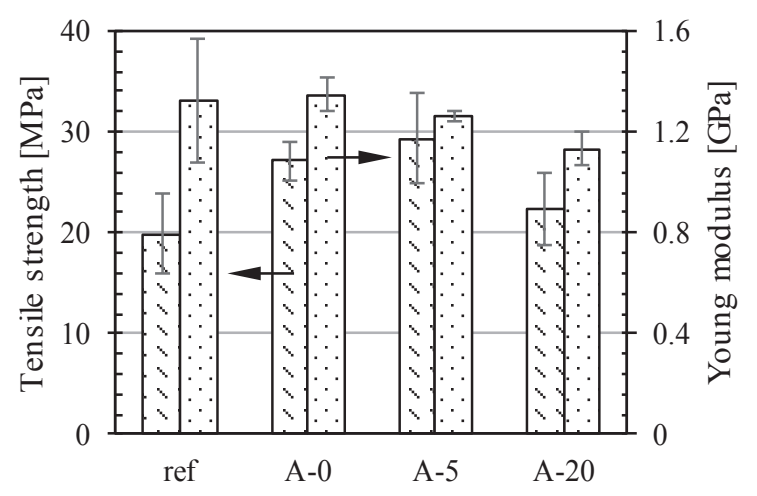

Fig. 5 The results of tensile test

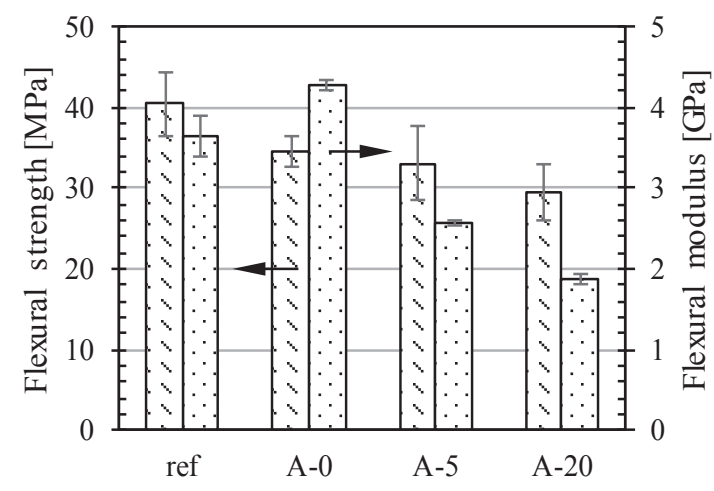

Fig. 6 The results of three-point bending test 
pieces, the flexural test results were much higher due to the thickness of the solid shell.

The results of the impact test show that samples with larger cell diameters exhibited much lower impact resistance (Fig. 7). Larger cell diameter cavities reacted to the test as stress concentration location. The impact modifier improved the impact strength of the samples by $18.42 \%$. The application of the flame-retardant even on small scale also greatly increased the resistance of the material to impact. One reason for this is that the cell diameters have decreased proportionally with the increase in viscosity, and another is due to the more favorable properties of the ethylene copolymer carrier. During the measurements, there was a repeated high standard deviation due to the different cell distribution of the samples.

\subsection{Flammability properties}

The UL 94 flammability test was carried out to fit with the strict requirements of a vertical arrangement. Samples containing $20 \%$ flame-retardant were consistent with the criterion of best flammability class of V0. The total burning time of the 5 specimens was 34.06 seconds, which corresponds to the strictest requirement of 50 seconds.

In the vertical test, the other samples could not be classified, the samples without the flame-retardant burned until reached the sample clamping. The sample containing $5 \%$ flame retardant also burned until reached the sample clamping. Non-classifiable samples of the vertical test were subjected to a horizontal test according to the specifications. The average burning rate of the sample containing the $5 \%$ flame-retardant was $14.72 \mathrm{~mm} / \mathrm{min}$. None of the specimens reached the maximum flame spread rate of $40 \mathrm{~mm} / \mathrm{min}$, so the sample containing $5 \%$ flame-retardant can be classified in class HB.

Foams containing no flame retardant did not meet the classification criteria.

\section{References}

[1] Nace, T. "We're Now At A Million Plastic Bottles Per Minute $91 \%$ Of Which Are Not Recycled", Forbes, [online] Available at: https://www.forbes.com/sites/trevornace/2017/07/26/million-plastic-bottles-minute-91-not-recycled/ [Accessed: 15 June 2019]

[2] Paci, M., La Mantia, F. P. "Competition between degradation and chain extension during processing of reclaimed poly(ethylene terephthalate)", Polymer Degradation and Stability, 61(3), pp. 417-420, 1998.

https://doi.org/10.1016/S0141-3910(97)00227-9

[3] Coccorullo, I., Di Maio, L., Montesano, S., Incarnato, L. "Theoretical and experimental study of foaming process with chain extended recycled PET", eXPRESS Polymer Letters, 3(2), pp. 84-96, 2009. https://doi.org/10.3144/expresspolymlett.2009.12

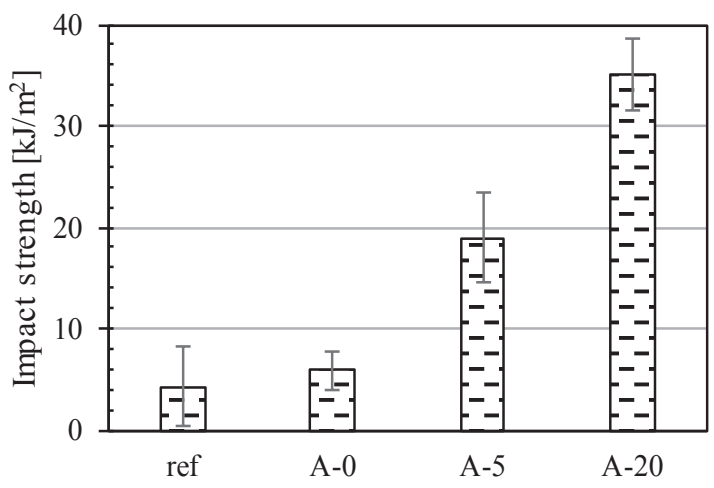

Fig. 7 The results of Charpy impact test

\section{Conclusion}

After the sample production and the measurements were made, it was found that the crystallized blue bottle regranulate is suitable for establishing a close-cell foam structure with the use of the flame-retardant additive. By using different additives, the material's mechanical properties were improved relative to the additive-free foam. Even with a small application of the flame-retardant additive, we can improve the cell structure. Regarding samples containing the flame-retardant, it has been found that foam formation was facilitated by flame retardant as demonstrated by several studies. In contrast, the results of the tensile test and flexural test showed a decrease in mechanical properties when using the flame-retardant. Increasing the rate of flame-retardant increases Charpy's impact strength and decreases density as well as the average cell diameter. The material containing $20 \%$ flame retardant meets the criteria of V0 flammabilty rating, which is one of the conditions of industrial applicability.

\section{Acknowledgement}

The publishing of this paper was supported by the ÚNKP18-2 New National Excellence Program of the Ministry of Human Capacities, Hungarian Government.

[4] Karayan, V. "'As Good as New' Chain Extender Restores Reclaimed Resins", Plastics Technology, 53(2), pp. 70-73, 2007.

[5] Turfa, E., Dogossy, G., Ronkay, F. "Reciklált PET tulajdonságainak javítása reaktív extrúzióval" (Improvement of properties of recycled PET with reactive extrusion), Anyagok Világa, 11(2), pp. 50-58, 2013. (in Hungarian)

[6] Ronkay, F., Kasza, D. "Reciklált PET műszaki alkalmazhatósága" (Development of engineering material based on recycled PET), Műanyag és Gumi, 51(3), pp. 88-91, 2014. (in Hungarian)

[7] Lyon, R. E., Janssens, M. L. "Polymer Flammability", U.S. Department of Transportation, Federal Aviation Administration, Office of Aviation Research, Washington, DC, USA, Rep. DOT/FAA/AR-05/14, 2005. 
[8] Szolnoki, B., Toldy, A., Konrád, P., Szebényi, G., Marosi, Gy. "Comparison of additive and reactive phosphorus-based flame retardants in epoxy resins", Periodica Polytechnica Chemical Engineering, 57(1-2), pp. 85-91, 2013.

https://doi.org/10.3311/PPch.2175

[9] Marosföi, B. B. "Nanoadalék-tartalmú égésgátolt poliolefin rendszerek fejlesztése" (Development of flame retarded polyolefine systems containing nanoparticles), PhD Thesis, Budapest University of Technology and Economics, 2009. (in Hungarian) [online] Available at: http://hdl.handle.net/10890/836 [Accessed: 15 June 2019]

[10] Ronkay, F., Molnár, B., Szalay, F., Nagy, D., Bodzay, B., Sajó, I. E., Bocz, K. "Development of Flame-Retarded Nanocomposites from Recycled PET Bottles for the Electronics Industry", Polymers, 11(2), article ID: 233, 2019. https://doi.org/10.3390/polym11020233

[11] Xue, B., Niu, M., Yang, Y., Bai, J., Song, Y., Peng, Y., Liu, X. "Multi-functional carbon microspheres with double shell layers for flame retardant poly (ethylene terephthalate)", Applied Surface Science, 435, pp. 656-665, 2018.

https://doi.org/10.1016/j.apsusc.2017.11.158
[12] Ghaderian, A., Haghighi, A. H., Taromi, F. A., Abdeen, Z., Boroomand, A., Taheri, S. M.-R. "Characterization of Rigid Polyurethane Foam Prepared from Recycling of PET Waste", Periodica Polytechnica Chemical Engineering, 59(4), pp. 296-305, 2015. https://doi.org/10.3311/PPch.7801

[13] Carosio, F., Cuttica, F., Di Blasio, A., Alongi, J., Malucelli, G. "Layer by layer assembly of flame retardant thin films on closed cell PET foams: Efficiency of ammonium polyphosphate versus DNA", Polymer Degradation and Stability, 113, pp. 189-196, 2015. https://doi.org/10.1016/j.polymdegradstab.2014.09.018

[14] Szabó, V. A., Dogossy, G. "Recycling of Mineral Water Bottles with Chemical Foaming", Acta Technica Jaurinensis, 10(2), pp. 157-167, 2017. https://doi.org/10.14513/actatechjaur.v10.n2.446

[15] Szabó, V. A., Dogossy, G. "Structure and properties of closedcell foam prepared from rPET", IOP Conference Series: Materials Science and Engineering, 426, article ID: 012043, 2018. https://doi.org/10.1088/1757-899X/426/1/012043 